\title{
PCR-Nachweis von C. difficile führt zu Überdiagnostik
}

Der molekulare Nachweis von Clostridium(C.)-difficile -Antigenen ist selbst bei entsprechender Symptomatik kein hinreichender Beweis für eine Infektion durch das Darmbakterium. Daran erinnern Ärzte der Universität von Sacramento. Wie sie bei Patienten ihrer Klinik demonstrieren konnten, haben Patienten mit positiver
PCR, aber negativem Toxintest eine ähnlich gute Prognose wie Patienten, bei denen beide Tests unauffällig sind. „Wenn man sich bei der CDI-Diagnose ausschließlich auf molekulare Tests verlässt, führt dies wahrscheinlich zu Überdiagnostik und Übertherapie“, warnen die Mediziner.

- JAMA Intern Med 2015;175:1792-1801

\section{Pädiatrie}

\section{Schützen Haustiere vor Asthma?}

Kinder, die in engem Kontakt mit Tieren leben, erkranken offenbar seltener an Asthma, wie eine schwedische Registerstudie zeigen konnte. Die Autoren analysierten Daten von 53.460 bzw. 1.729 Vorschulkindern sowie 22.629 bzw. 958 Schulkindern, die während ihres ersten Lebensjahrs mit einem Hund oder auf dem Bauernhof gelebt hatten. Diese Kinder hatten den Berechnungen der Wissenschaftler zufolge ein geringeres Asthmarisiko als gleichaltrige Kinder ohne intensiven Tierkontakt. Für die auf dem Bauernhof lebenden Kinder sank die Wahrscheinlichkeit um rund 30\% (Vorschulkinder) bzw. 50\% (Schulkinder), an Asthma zu erkranken. Auch ein Hund im Haushalt senkte das Asthmarisiko signifikant. - JAMA Pediatr 2015;169:e153219

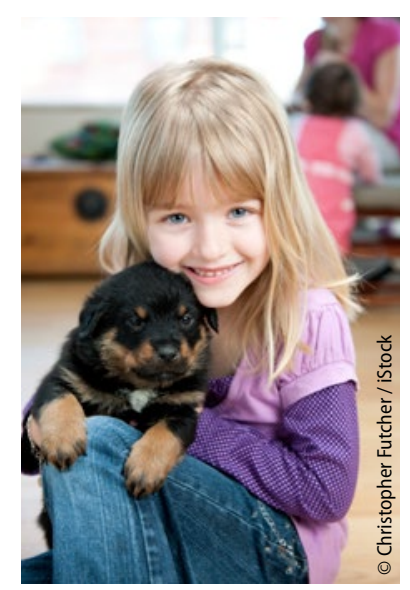

\section{Studie mit Schweizer Kindern}

\section{Sind Autobahnen krebserregend?}

Kinder, die in einem Umkreis von weniger als $100 \mathrm{~m}$ zu Autobahnen oder Schnellstraßen leben, laufen offenbar ein höheres Risiko, an Leukämie zu erkranken.

Forscher der Universität Bern griffen für ihre Kohortenstudie auf Daten von mehr als zwei Millionen Kindern zurück, die aus den Jahren 1990 bis 2008 stammten und genaue Angaben zu den jeweiligen Wohnorten umfassten. 1.783 der Kinder erkrankten an Krebs, davon 532 an Leukämie. Abgeglichen nach sozioökonomischen Fakto- ren, ionisierender Hintergrundstrahlung und Exposition gegen elektromagnetische Felder ergab sich für Kinder, die weniger als $100 \mathrm{~m}$ weit von einer Autobahn bzw. Schnellstraße entfernt wohnten, ein im Vergleich zu den am geringsten exponierten Kindern (Abstand $\geq 500 \mathrm{~m}$ ) um 47\% gesteigertes Leukämierisiko. Für die akute lymphoblastische Leukämie (ALL) war das Risiko um 53\% erhöht.

- Eur J Epidemiol 2015, online 2. November doi: 10.1007/s10654-015-0091-9
Dr. med.

Brigitte Moreano Stellvertretende Chefredakteurin brigitte.moreano@ springer.com

\section{US-Daten}

\section{Schizophrenie kostet fast 30 Lebensjahre}

Schizophreniekranke haben eine deutlich verringerte Lebenserwarung. Das bestätigte die Analyse der Daten von über 1,1 Millionen Schizophreniepatienten aus den USA. Im Laufe von im Schnitt 4,2 Jahren verstarben rund 74.000 Patienten (6,5\%) 3,7-mal mehr als in der vergleichbaren Allgemeinbevölkerung. Damit sterben Schizophreniekranke im Schnitt 28,5 Jahre früher. 35\% der Patienten starben an HerzKreislauf-Erkrankungen und $17 \%$ an Krebs. Hier war die Sterberate knapp verdoppelt. Die Sterberate bei COPD war zehnfach und die durch Influenza und Pneumonien siebenfach erhöht. Etwa 15\% der Todesfälle ließen sich auf nicht natürliche Ursachen zurückführen. Mehr als die Hälfte davon ging auf das Konto von Unfällen. Die Suizidrate lag bei Männern über dem Dreifachen und bei Frauen über dem Siebenfachen gegenüber der Allgemeinbevölkerung. Substanzmissbrauch, insbesondere Alkohol, war Ursache für 8,2\% der Todesfälle. Ein Teil der Exzessmortalität lässt sich auch durch den bei Schizophreniepatienten immer noch stark erhöhten Raucheranteil erklären.

- JAMA Psychiatry 2015; epub 28.10.2015, doi:10.1001/jamapsychiatry.2015.1737

\section{LESEHITS AUF SPRINGERMEDIZIN.DE}

Versorgung von Flüchtlingen:

$\rightarrow$ www.springermedizin.de/aerztehelfen-fluechtlingen

Aktuelle Berichte vom US-Herzkongress: $\rightarrow$ www.springermedizin.de/aha-2015 